\title{
INDUCTION OF MUTATION IN STAPHYLOCOCCUS AUREUS BY ETHYLMETHANE SULPHONATE
}

\author{
J. C. M. van DeR ViJver, Mary M. van Es-Boon AND M. F. Michel \\ Department of Clinical Microbiology and Antimicrobial Therapy, Erasmus University, \\ Rotterdam, The Netherlands
}

$S_{T A P H Y L O C O C C U S}$ AUREUS produces many extracellular factors that may be related to pathogenicity or determine differences in virulence. However, our knowledge of the contribution of individual factors to virulence is still inadequate, and it is assumed that the virulence of a strain is determined by a combination of factors.

One approach to the study of virulence factors is to purify the extracellular products and to investigate their effects on tissues in vitro and in vivo; in some cases, the protective effect of active or passive immunisation with the products has also been studied. Certain products have received particular attention because it was thought that they might interfere with the host response or have a direct toxic effect on tissues. However, it has not been possible to demonstrate in this way that factors associated with virulence, such as $\alpha$-haemolysin (Arbuthnott, 1970), $\beta$ - and $\delta$-haemolysin (Wiseman, 1970), P-V leucocidin (Mudd, Gladstone and Lenhart, 1965), free coagulase (Cawdery et al., 1969), staphylokinase (Noble, 1966) or lipase (Noble, 1966; Jessen et al., 1969) contribute in vivo to the virulence of $S$. aureus.

A classical approach to the study of virulence factors is the comparison of virulent and avirulent strains. Some strains of $S$. aureus appear to be more virulent for man, because they cause more epidemics (Williams, 1963). Staphylococcal strains that were epidemic for man were found to be more liable to produce skin lesions in mice than were non-epidemic strains (Noble, 1966). Mouse virulence and human epidemicity were correlated with the production of $\alpha$ - and $\beta$-lysin, and staphylokinase was also found to occur more in virulent strains than in non-virulent ones. Foster (1971) suggested, however, that higher lesion scores in the mouse were more correlated with human epidemicity than with virulence as such.

Agarwal (1967) showed that $S$. aureus strains can be divided into " mouse-virulent" strains and " non-virulent" strains, as determined by the ability of these strains to inhibit the inflammatory response in the host. The inflammation-inhibiting factor was isolated by Hill (1968) from the cell wall. This cell-wall aggressin was also found to be active in the human host (van der Vijver, van Es-Boon and Michel, 1974).

A third method of studying virulence factors is to make use of mutants of a strain of known virulence. Few authors so far have undertaken the induction of mutants in $S$. aureus (Kapral and Li, 1960; McClatchy and Rosenblum, 1966).

The present paper describes mutagenesis in $S$. aureus caused by the alkylating substance ethylmethane sulphonate (EMS), which has been found to have a mutagenic effect while permitting a high level of survival in Gramnegative organisms (Loveless and Howarth, 1959; Hayes, 1968). The objective was to isolate mutants that differed from the wild type in one property only and subsequently to determine experimentally the contribution of individual extracellular products to the virulence of $S$. aureus.

Received 5 July 1974; amended version accepted 29 Oct. 1974.

J. MED. MICROBIOL.-VOL. 8 (1975) 


\section{MATERIALS AND METHODS}

Strains. Mutants were induced in three strains. Strain V2, isolated from the blood of a patient with staphylococcal sepsis, was resistant to penicillin and streptomycin. Strains V4 and V5, isolated from patients with osteomyelitis, were penicillin resistant. To make it easier to identify these strains and their mutants, novobiocin-resistant variants were selected by serial culture in increasing concentrations of novobiocin, varying from 0.1 to $10 \mu \mathrm{g}$ per ml. The selected strains, which were resistant to $10 \mu \mathrm{g}$ per $\mathrm{ml}$ of novobiocin, were used for all the experiments described here. Novobiocin resistance was chosen as a marker because only $1 \%$ of 500 strains of Staphylococcus epidermidis isolated from clinical material were found to be resistant to novobiocin. The strains were stored in the freeze-dried form.

Strain Wood 46 was no. NCTC 7121.

Key to symbols used. Coag $=$ free coagulase; $b c=$ bound coagulase; $\alpha$-lys $=\alpha$-lysin; $\delta$-lys $=\delta$-lysin $;$ kin $=$ staphylokinase $;$ dnase $=$ deoxyribonuclease; $t w 20(80)=$ Tween 20 (80)-splitting lipase; phos = phosphatase; hya $=$ hyaluronidase; leuc $=\mathrm{P}-\mathrm{V}$ leucocidin; gelat = gelatinase; $m t l=$ mannitol fermentation; "-" means that the given activity could not be demonstrated; " $l$ " (= leaky) means reduced activity; $\phi r=$ phage resistant.

Media. The media used were meat broth with the addition of $1 \%$ Difco Bacto Peptone and $0.5 \% \mathrm{NaCl}$, and Oxoid Blood Agar Base containing defibrinated sheep blood $5 \%(\mathrm{v} / \mathrm{v})$. Antibiotic-sensitivity tests were performed on DST Agar (Oxoid) with Multodiscs (Oxoid) bearing various antibiotics and single disks (Difco) containing $5 \mu \mathrm{g}$ of novobiocin.

Bacterial counts were made according to the method of Miles, Misra and Irwin (1938).

The virulence test for mice was done as described by van der Vijver et al. (1974).

\section{The induction of mutants with EMS}

EMS (Koch-Light) was diluted 1 in 25 before use with a 1 in 8 aqueous dilution of a stock salt solution of the following composition: $\left(\mathrm{NH}_{4}\right)_{2} \mathrm{Fe}\left(\mathrm{SO}_{4}\right)_{2} .6 \mathrm{H}_{2} \mathrm{O}, 28 \mathrm{mg} ; \mathrm{MgSO}_{4} .7 \mathrm{H}_{2} \mathrm{O}$, $200 \mathrm{mg} ; \mathrm{NH}_{4} \mathrm{Cl}, 8 \mathrm{~g} ; \mathrm{KH}_{2} \mathrm{PO}_{4}, 18 \mathrm{~g} ; \mathrm{K}_{2} \mathrm{HPO}_{4}, 30 \mathrm{~g}$; distilled water, $1000 \mathrm{ml}$; the solution was adjusted to $p \mathrm{H} 6.8$ and sterilised by autoclaving. One $\mathrm{ml}$ of the diluted EMS solution was added to $1 \mathrm{ml}$ of an 18-h culture which was then incubated at $37^{\circ} \mathrm{C}$ for $2 \mathrm{~h}$ and then centrifuged. The alkylation process was blocked by washing with $5 \%$ sodium thiosulphate, which had been sterilised by filtration through a $0.20 \mu \mathrm{m}$ Millipore membrane filter (Bautz and Freese, 1960). The sediment was taken up in $2 \mathrm{ml}$ of meat broth, and $0.125 \mathrm{ml}$ was transferred into $5 \mathrm{ml}$ of meat broth and incubated at $37^{\circ} \mathrm{C}$ for $18-36 \mathrm{~h}$, until visible growth was observed. The turbidity was measured in a spectrophotometer at $650 \mathrm{~nm}$ and at an optical density (OD) of less than $\mathbf{0 . 2 5 0}$. The number of colony-forming units (c.f.u.) was determined by reference to a standard graph. Standard plots were made for each strain individually, and showed a linear relation between the number of c.f.u. and the OD in the range from 0 to 0.250 . Four standard drops (each of $0.025 \mathrm{ml}$ ) of a suitable dilution were then transferred to indicator plates and spread out; we tried to get from 10 to 40 colonies per plate. When more than two properties were investigated, the culture was first inoculated on agar plates and replica plating was performed with a velvet pad on a block. When phenotypically changed colonies were observed on the indicator plates, they were investigated again. When the change was found to breed true, the resistance spectrum was determined. If this agreed with that of the wild type, the strains were considered to be mutants. They were then investigated for properties of $S$. aureus, and phage typed. All mutants were designated by a letter denoting the mutation experiment and a serial number. They were stored in freeze-dried form.

\section{Plate methods for testing the properties of staphylococci}

Several plate methods were screened for their suitability for the isolation of mutants. All the plate methods described here gave clearly visible effects round isolated colonies. Plate methods were used for the determination of staphylokinase (Lack and Wailling, 1954), 
phosphatase (Barber and Kuper, 1951), hyaluronidase (Smith and Willet, 1968), deoxyribonuclease (DNAase, Oxoid), Tween 20- and Tween 80-splitting lipase (Sierra, 1957), and gelatinase (Baird-Parker, 1963). For the selection of coagulase mutants, we used a solid medium described by van der Vijver, Kraayeveld and Michel (1972). The tube-coagulase test was performed with Difco plasma according to the manufacturer's instructions, and the slide test as described by Cadness-Graves et al. (1943).

Production of $\alpha$-, $\beta$ - and $\delta$-lysin was tested by culture on Nutrient Agar (Oxoid) containing $5 \%$ washed erythrocytes of rabbit, man or sheep. The strains were stroke-inoculated at right angles to a filter strip soaked in $\alpha$-antitoxin (Burroughs and Wellcome, $150 \mathrm{IU}$ per $\mathrm{ml}$ ). Plates containing sheep erythrocytes were seeded in duplicate and one was incubated anaerobically for $48 \mathrm{~h}$ at $37^{\circ} \mathrm{C}$; all of the other plates were incubated in a mixture of $15 \% \mathrm{CO}_{2}$ and $85 \%$ air. The haemolysin pattern was read according to the criteria of Elek and Levy (1950). Non-haemolytic mutants were selected on plates containing rabbit or human erythrocytes for the detection of $\alpha$-lysin or $\delta$-lysin mutants respectively.

Leucocidin mutants were screened by spreading an EMS-treated culture on plates of coagulase-test medium, and by stroke-plating coagulase-positive colonies subsequently at right angles to filter strips soaked in antileucocidin serum. The plates used for this purpose contained casein yeast diffusate (CCY) medium 3-4 mm thick, with $1 \frac{1}{2} \%$ Noble Agar (Difco). The plates were incubated for $18 \mathrm{~h}$ at $37^{\circ} \mathrm{C}$ and were read after $48 \mathrm{~h}$ at room temperature. Strain V4 gave two lines that were not given by a leucocidin mutant BB12 $\left(\alpha-l y s^{t}\right.$, $\delta$-lys ${ }^{-}$, leuc $^{-}$; see table II). However, these lines were given by $\alpha$-lysin mutants. Although it was shown by Ouchterlony immunodiffusion that our own anti-leucocidin serum gave three lines with leucocidin as antigen, while the international reference antileucocidin serum gave two lines, this method was accepted for screening purposes. All colonies that did not give one or both lines were examined further for loss of leucocidin production.

\section{Tube methods for testing the properties of staphylococci}

Metabolic characteristics such as aerobic and anaerobic production of acid from glucose and mannitol and aerobic production of acid from lactose, maltose and glucose, production of acetoin and the ability to reduce nitrates and nitrites were investigated by the tube methods of Baird-Parker (1963).

Determination of $\boldsymbol{P}-\boldsymbol{V}$ leucocidin and antileucocidin. Production of P-V leucocidin (leucocidin) was investigated by the methods of Gladstone and van Heyningen (1957) with the following modifications. The CCY medium was as described by Woodin (1959). The production of leucocidin was performed in $250-\mathrm{ml}$ plastic tissue-culture bottles shaken in a vertical position at $37^{\circ} \mathrm{C}$. Three $\mathrm{ml}$ of CCY medium was seeded with $0.3 \mathrm{ml}$ of an $18-\mathrm{h}$ culture in CCY medium. After shaking for $8 \mathrm{~h}$ at $37^{\circ} \mathrm{C}, 30 \mathrm{ml}$ of $\mathrm{CCY}$ medium at $37^{\circ} \mathrm{C}$ were added to the culture. After a further $8-16 \mathrm{~h}$, the culture was centrifuged at $4^{\circ} \mathrm{C}$ and the supernate examined for leucocidin content. The leucocidin was estimated roughly by determination of the minimum leucocidal dose (MLeD), and more accurately by determination of the $\mathrm{L}+$ dose per $\mathrm{ml}$ (Gladstone and van Heyningen, 1957). The antiserum used was prepared by immunisation of a rabbit (Gershon and Gladstone, 1968) with a partially purified leucocidin preparation $(80 \mathrm{~L}+$ per $\mathrm{ml}$ ) manufactured by Organon (Oss, the Netherlands) according to the method described by Woodin (1959). The antiserum obtained (40 IU per $\mathrm{ml}$ ) was standardised against the international reference preparation (Skegg and Anderson, 1969). The antileucocidin assay was performed according to the method of Gladstone et al. (1962). For comparison of the leucocidin production of different strains the same batch of CCY medium was always used, and the leucocidin content was determined at the same time, generally after shaking for 8-12 h.

Estimation of haemolytic activity of culture supernates. For these estimations we used 300-ml flasks closed with rubber stoppers bearing two pieces of glass tubing. Fifty $\mathrm{ml}$ of Todd Hewitt broth (Difco) was seeded with $0.5 \mathrm{ml}$ of an 18-h culture. A mixture of $30 \% \mathrm{CO}_{2}$ and air was passed through the culture for $3 \mathrm{~min}$., after which the tubes were closed and the culture was incubated at $37^{\circ} \mathrm{C}$ for $18 \mathrm{~h}$ with gentle shaking. It was then centrifuged and 
serial doubling dilutions of the supernate were made in $0.5 \mathrm{ml}$ of phosphate-buffered saline (PBS: $0.155 \mathrm{M} \mathrm{NaCl} ; 0.01 \mathrm{M}$ phosphate per litre, $p \mathrm{H} 6.9$ ); $0.5 \mathrm{ml}$ of $2 \%$ washed rabbit or human erythrocytes was added to each tube. The haemolytic activity was estimated visually, the dilution giving $50 \%$ haemolysis after $1 \mathrm{~h}$ at $37^{\circ} \mathrm{C}$ being considered to contain $1 \mathrm{MHD}$. A tube containing $1 \mathrm{ml}$ of erythrocyte suspension and $3 \mathrm{ml}$ of phosphate buffer in distilled water was used as standard for $50 \%$ haemolysis. Neutralisation with $\alpha$-antitoxin and inactivation by heating were carried out as described by Arbuthnott et al. (1969). In preliminary experiments it was found that culture supernates of the wild-type strain V4 could be neutralised completely by 1-2 IU $\alpha$-antitoxin per $\mathrm{ml}$ filtrate. Therefore all neutralisation experiments were performed with an excess of $6 \mathrm{IU} \alpha$-antitoxin per $\mathrm{ml}$ of crude toxin.

\section{In-vitro studies of growth rate of staphylococci}

A $100-\mathrm{ml}$ volume of broth was seeded with about $1 \times 10^{3}$ colony-forming units (c.f.u.) and incubated at $37^{\circ} \mathrm{C}$ in a water bath. The number of c.f.u. were counted each hour. A growth curve was plotted, and the growth constant $\mathrm{K}$ per $\mathrm{h}$ was determined from the linear portion of the curve by the method of Meynell and Meynell (1965).

\section{Phage procedures and phage typing of staphylococci}

The methods of Blair and Williams (1961) were followed. The phages Noble (N), 88, $83 \mathrm{~A}, 84,44 \mathrm{~B}$ and 85 were added to the standard typing phages, and all were used at routine test dilution $(\mathrm{RTD} \times 100)$. Phage induction was performed by exposure for $30 \mathrm{~min}$. to $0.5 \mu \mathrm{g}$ of mitomycin C per ml (Otsuji et al., 1959). Phage propagation was performed in broth, starting from a plaque. Strain S57 was used as a universal indicator strain for the phage titrations (Winkler et al., 1965). The serological group of the phages was determined by the method of Burnet, Keogh and Lush (1937) with group-A, -B and -F antisera kindly supplied by Dr Elizabeth H. Asheshov (Central Public Health Laboratory, Colindale, London). For curing experiments, specific antiphage sera were prepared in rabbits by daily intravenous injection of $10^{10}$ plaque-forming units for a week and a booster dose on the 14th day. For curing of lysogenic phage, a culture was grown for $16 \mathrm{~h}$ in the presence of antiphage serum $(20 \% \mathrm{v} / \mathrm{v})$. Two $\mathrm{ml}$ of this culture were used for seeding $3 \mathrm{ml}$ of broth containing mitomycin $\mathrm{C}$ (final concentration $0.5 \mu \mathrm{g}$ per $\mathrm{ml}$ ) and fresh antiphage serum (final volume $40 \%$ ). After incubation for $30 \mathrm{~min}$. the culture was spread on agar plates to obtain separate colonies. Individual colonies were then tested for loss of immunity by crossstreaking with the phage. The cured strains were lysogenised by spotting the phages on flooded plates. Secondary growth was tested for immunity after having been subcultured several times.

TABLE I

Lesion score 48 h after subcutaneous injection of Staphylococcus aureus in groups of five mice

\begin{tabular}{|c|c|c|c|c|c|}
\hline \multirow{2}{*}{$\begin{array}{l}\text { Strain } \\
\text { number }\end{array}$} & \multirow{2}{*}{ Dose } & \multicolumn{3}{|c|}{$\begin{array}{l}\text { Number of mice with } \\
\text { a lesion score* of }\end{array}$} & \multirow{2}{*}{$\begin{array}{l}\text { Mean lesion } \\
\text { score }\end{array}$} \\
\hline & & 0 & 1 & 2 & \\
\hline $\begin{array}{l}\text { V2 } \\
\text { V4 } \\
\text { V5 } \\
\text { Wood } 46\end{array}$ & $\begin{array}{l}6.1 \times 10^{5} \\
5.8 \times 10^{5} \\
8.4 \times 10^{5} \\
8.8 \times 10^{5}\end{array}$ & $\begin{array}{l}0 \\
0 \\
1 \\
5\end{array}$ & $\begin{array}{l}5 \\
3 \\
4 \\
0\end{array}$ & $\begin{array}{l}0 \\
2 \\
0 \\
0\end{array}$ & $\begin{array}{l}1.0 \\
1.4 \\
0.8 \\
0\end{array}$ \\
\hline
\end{tabular}

$* 0=$ No lesion; $1=$ pus, infiltration, or area of necrosis with a diameter less than $5 \mathrm{~mm}$; $2=$ necrotic area larger than $5 \mathrm{~mm}$. 


\section{RESULTS}

\section{Selection of strains for induction of mutants}

The strains V2 (phage-typing pattern 80/81), V4 (phage-typing pattern 29) and V5 (lysed by phage $\mathrm{N}$ ), which had given rise to severe infections in man, were selected initially for induction of mutants. The strains had characteristics that might be associated with virulence. They were positive for bound coagulase, and produced free coagulase, $\alpha$ - and $\delta$-lysin, leucocidin, staphylokinase, hyaluronidase, DNAase, Tween 20- and Tween 80-splitting lipase, and phosphatase; $\beta$-lysin, however, was not formed. The virulence of each strain for mice was determined by subcutaneous injection of about $1 \times 106$ c.f.u. into each of five mice. "Mouse-virulent" strains give lesions at this dose, whereas " nonvirulent" strains, such as strain Wood 46, do not (Hill, 1968). Table I shows the lesion scores for the three strains and for strain Wood 46; strains V2, V4 and V5 are "mouse-virulent", since they gave clearly visible lesions, whilst strain Wood 46 did not. At a later stage of the investigation, a cell-wall preparation of strain V4 was investigated for aggressin activity according to the method described by Hill (1968) and aggressin activity was demonstrated (see van der Vijver et al. 1974).

\section{Induction of mutation with EMS : preliminary results}

Strain V2 was treated five times with EMS, and a search for coagulase mutants was made in each experiment. Loss of $\alpha$-lysin production was investigated simultaneously in three of these experiments, of staphylokinase in two and of DNAase also in two. The number of colonies investigated varied from 300 to 800 per experiment. In one experiment in which a search was made for $\alpha$-lysin mutants, two colonies of the 690 investigated were found to give

TABLE II

Number of colonies investigated and mutants of strain V4 found after induction of mutation with ethylmethane sulphonate

\begin{tabular}{|c|c|c|c|}
\hline $\begin{array}{c}\text { Mutation } \\
\text { experiment }\end{array}$ & $\begin{array}{l}\text { Properties } \\
\text { tested for }\end{array}$ & $\begin{array}{l}\text { Number of } \\
\text { colonies }\end{array}$ & Mutants* \\
\hline B & $\begin{array}{l}\text { coagulase } \\
\alpha \text {-lysin }\end{array}$ & $\begin{array}{l}410 \\
500\end{array}$ & $\begin{array}{l}\text { B1 }\left(\text { coag }^{l}\right) \\
\text { B21 }\left(\alpha-l y s^{l}\right) \\
\text { B29 }\left(\text { coag }^{l}, \alpha-l y s^{-}, \text {dnase }^{l}, \text { leuc }^{l}\right) \\
\text { B22 }\left(\alpha-l y s^{-}, \text {kin }^{-}, \text {dnase }^{l}, \text { hya }^{l}, \text { leuc }^{l}\right) \\
\text { B17 }\left(\text { coag }^{l}, \alpha-\text { lys }^{l}, \delta-\text { lys }^{l}, \text { kin }^{l}, \text { dnase }^{l}, \text { leuc }^{l}\right)\end{array}$ \\
\hline BB & $\begin{array}{l}\text { coagulase } \\
\alpha \text {-lysin }\end{array}$ & $\begin{array}{l}680 \\
680\end{array}$ & 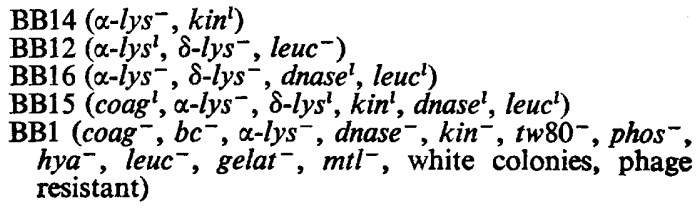 \\
\hline
\end{tabular}

* See Methods for a key to the symbols used. 
reduced haemolysis. Further investigation by the method of Elek and Levy (1950) showed that these strains had lost the ability to produce $\delta$-lysin.

Better results were obtained with strain V4, in which mutants were induced four times. A search was made four times for coagulase and $\alpha$-lysin mutants, and twice for DNAase mutants. In two induction experiments, a large number of mutants were found. The results summarised in table II show the wide variety of mutants produced.

Similar results were obtained with strain V5, in which mutants were induced four times and in which a large variety of mutants was also found.

A number of variants, which were found frequently in later induction experiments, had-like mutant BB1-lost all properties characteristic of $S$. aureus. These strains generally formed white colonies, showed a markedly lower growth rate in broth and were always insensitive to the phages of the phage-typing system of $S$. aureus. It is unlikely that these results were due to contamination, because these strains had the same antibiotic-resistance pattern as the wild type and were resistant to novobiocin.

Because strain V4 gave two mutants, B1 ( coagl $\left.^{l}\right)$ and B21 $\left(\alpha-l y s^{l}\right)$, suitable for comparative virulence experiments, all further induction experiments were performed with this strain. Mutants of strain V2, which was preferable because of the characters that we associate with the phage-type $80 / 81$, were found to be more difficult to induce. This strain was therefore not chosen.

\section{Induction of mutation in strain $V 4$}

In 43 separate induction experiments, strain V4 was treated with EMS. In a number of these experiments, several phenotypically identical mutants were found. These mutants were probably not induced independently but arose from the multiplication of a single mutant. Loss of $\delta$-lysin production was always combined with an appreciable reduction in the ability to produce leucocidin (see below). The other mutants did not show any systematised linked loss of properties.

The experiments were now specifically aimed at getting mutants that differed from the wild type in one or two properties only. Mutants that differed from the wild type in more than two properties were observed frequently. Apart from two examples (see table III), these mutants will not be discussed further. They showed the same pluriformity as the mutants indicated in table II.

The mutants that had lost only one or two properties and were found suitable for virulence experiments will now be discussed.

Coagulase mutants. Only one coagulase mutant was found in six induction experiments. The mean (M) number of colonies investigated was 360 , and the range (R) was $160-680$. This strain $\mathrm{B} 1\left(\right.$ coag $\left.^{l}\right)$, unlike the wild type, gave no coagulation in the tube coagulase test after 2,4 and $6 \mathrm{~h}$. However, as some coagulation was sometimes found after $24 \mathrm{~h}$, this strain was considered to be a leaky mutant.

$\alpha$-Lysin mutants. In three of the 12 induction experiments $(M=560$; $R=300-1500$ ), $\alpha$-lysin mutants were found. In three other induction experiments 
colonies with reduced haemolysis were observed; this appeared to be due to loss of $\delta$-lysin. The three $\alpha$-lysin mutants showed no $\alpha$-lysin activity when tested by the method of Elek and Levy (1950). However, the culture supernates still showed lytic activity characteristic of $\alpha$-lysin (see below), so these strains must be considered as leaky mutants. The strains B21 $\left(\alpha-l y s^{l}\right)$, BH5 $\left(\alpha-l y s^{l}\right)$ and a double mutant BT22 $\left(\alpha-l y s^{-}\right.$, leucl $\left.{ }^{l}\right)$ were used for subsequent virulence studies reported in the following paper (van der Vijver, van Es-Boon and Michel, 1975).

$\delta$-Lysin mutants. One $\delta$-lysin mutant was found in one of the 13 induction experiments $(M=310 ; R=200-750)$. This strain produced only minimum amounts of leucocidin, as was the case with the three $\delta$-lysin mutants mentioned earlier. To investigate whether loss of $\delta$-lysin was associated with a diminished leucocidin production, mutation was induced five times more with EMS; 600-800 colonies were investigated per experiment. Three $\delta$-lysin mutants were found. All seven $\delta$-lysin mutants obtained from various induction experiments produced only 4-10 MLeD of leucocidin, whilst the wild type gave 200-400 MLeD. Only strain BS36 ( $\delta$-lys', leucl) was used for the subsequent virulence experiments reported in the following paper.

Leucocidin mutants. Five induction experiments were performed, and 100 coagulase-positive colonies were screened for leucocidin loss per experiment. The method used was not very reliable; differences in the number or intensity of the lines were sometimes found and, according to the MLeD determination, these were not due to loss of leucocidin production. In one of the experiments, however, two colonies were observed that gave no lines at all. These strains produced only $5 \mathrm{MLeD}$, whilst the wild type produced $200 \mathrm{MLeD}$. The two strains were identical in all respects. Strain L62 (leucl) was used for the virulence experiments.

Staphylokinase mutants. Staphylokinase mutants were found in two of the 12 induction experiments $(M=240 ; R=100-500)$. The mutant strains did not differ from each other. Strain BF34 (kin-) was used for the virulence experiments.

Other experiments on the induction of mutation. Mutants with isolated loss of DNAase were not found in 22 induction experiments $(M=250 ; R=180$ 500). DNAase-negative colonies were in all cases found to be mutants that had lost a large number of other properties as well. This was also the case with hyaluronidase mutants, which were looked for in 11 experiments $(M=250$; $\mathrm{R}=250-500$ ). A search for Tween-splitting lipase mutants was made in only two experiments ( 400 and 500 colonies); such mutants were not found.

Further studies on selected mutants. All the mutants used for virulence experiments were repeatedly examined for staphylococcal properties mentioned in the Methods section. All the mutants were found to be stable; reversions were not observed. The growth rate in vitro and the phage typing pattern of these mutants are given in table III; only the mutants B29 and BB16, both of which were changed in more than two properties, had a lower $\mathrm{K}$ value than the wild type. In addition, the phage-typing patterns of strains BF34 (kin-) and L62 $($ leucl) were found to differ from that of the wild type. This is unlikely to 
have been due to contamination because the antibiotic-resistance pattern remained unchanged.

Investigations of the differences in phage-typing pattern of the wild type and the mutants BF34 (kin-), and L62 (leucl)

The difference in phage-typing pattern between the wild type and mutants BF34 ( $\mathrm{kin}^{-}$) and L62 (leucl) might indicate that these mutations are not caused by a structural alteration in the chromosome but by a change in the prophage genotype; it is known that loss or acquisition of prophage is often associated with a change in the phage-typing pattern. To test this hypothesis, we made use of the fact that a strain that has been cured of a prophage becomes sensitive to that phage. Induction of phage formation in the wild type strain V4 was therefore performed by exposure to a low dose of mitomycin C. A phage lysate was obtained with a strength of RTD $\times 5000$ as determined by titration on strain S57. Mutants BF34 (kin-) and L62 (leucl) were found to be sensitive to this phage lysate, unlike the other mutants mentioned in table III. This finding makes it very likely that the prophage genotypes of these strains differ from that of the wild type by loss of prophage, and that loss of staphylokinase and leucocidin production might be associated with loss of prophage. The ability of the wild type to produce leucocidin and staphylokinase would thus seem to be based on lysogenic conversion.

These possibilities were investigated by curing the wild-type strain V4 of all prophages, a group-B, $-\mathrm{A}$ and $-\mathrm{F}$ phage being eliminated in succession; in this way, a phage-free variant $\mathrm{CV} 4(-\mathrm{B}, \mathrm{A}, \mathrm{F})$ was obtained. This strain was staphylokinase negative and produced only minimum amounts of leucocidin. The cured variants were relysogenised with pure group-B, $-\mathrm{A}$ and $-\mathrm{F}$ phage. The phage-typing patterns and the ability of the relysogenised and non-lysogenic variants to produce leucocidin and staphylokinase were compared. From this comparison it could be concluded that the wild type is converted to greater

TABLE III

Growth rate $(K \text { per } h)^{*}$ and phage-typing pattern of mutants and the wild-type strain $V 4$

\begin{tabular}{|c|c|c|}
\hline Strain & $\mathrm{K}$ per $\mathrm{h}$ & $\begin{array}{l}\text { Phage-typing } \\
\text { pattern }\end{array}$ \\
\hline 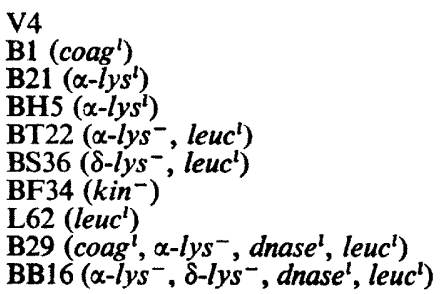 & $\begin{array}{l}0 \cdot 62 \\
0 \cdot 62 \\
0 \cdot 63 \\
0 \cdot 65 \\
0 \cdot 63 \\
0 \cdot 62 \\
0 \cdot 62 \\
0 \cdot 63 \\
0 \cdot 42 \\
0.48\end{array}$ & $\begin{array}{l}29 \\
29 \\
29 \\
29 \\
29 \\
29 \\
29 / 81 /+ \\
29 / \mathrm{N} / 7 /+ \\
29 \\
29\end{array}$ \\
\hline
\end{tabular}

* See Methods. 
leucocidin production by a group-A phage and staphylokinase production by a group-F phage (van der Vijver van Es-Boon and Michel, 1972).

Strain L62 (leucl) was sensitive only to the group-A phage, and strain BF34 $\left(\mathrm{kin}^{-}\right)$to the group-F phage (table IV). The strains were relysogenised with the respective phages. The phage-typing patterns and the production of leucocidin and staphylokinase were then compared. The results given in table IV show that after lysogenisation, strain L62 (leucl) again produced as much leucocidin as the wild type. Similarly, strain BF34 (kin $)$ became staphylokinase positive after lysogenisation. Moreover, lysogenisation restored the original phage-typing pattern. It was therefore concluded that the change in production of leucocidin and staphylokinase by these mutants was indeed due to loss of prophage.

\section{Haemolytic activity of culture supernate}

Culture supernates of the wild-type strain V4 and the mutants mentioned in table III were titrated for haemolytic activity against rabbit and human RBC. The experiment was performed twice, with two different culture supernates. The titration results and the haemolysin patterns as described by Elek and Levy (1950) are presented in table V. The results for the two culture supernates agreed well. Mutants B1 ( coagl), BF34 ( kin $\left.^{-}\right)$, L62 (leucl) and the wildtype strain V4 gave the same haemolysin patterns on blood agar, and culture supernates of these strains had the same titres in haemolysin tests with RBC. These mutants and the wild type thus appear to make the same amount of haemolysin, probably $\alpha$ - and $\delta$-lysin. Culture supernates of the strains that showed loss of haemolysin activity on blood agar had lower titres than the wild type. The supernates were further tested for neutralisation with $\alpha$ antitoxin and for thermostability, to assess the extent to which the strains had

TABLE IV

Comparison of some characteristics of the wild-type strain V4, mutant $L 62$ and its variant $L 62(A)$ lysogenised with group-A phage, and mutant BF34 (kin-) and its variant BF34(F) lysogenised with group-F phage

\begin{tabular}{|c|c|c|c|c|c|}
\hline \multirow{2}{*}{ Strain } & \multicolumn{2}{|c|}{$\begin{array}{l}\text { Sensitivity to the } \\
\text { stated phage** }\end{array}$} & \multirow{2}{*}{$\begin{array}{l}\text { Phage-typing } \\
\text { pattern }\end{array}$} & \multicolumn{2}{|c|}{ Production of } \\
\hline & A & pilage & & $\begin{array}{l}\text { leucocidin } \\
(\mathbf{L}+\text { per } \mathrm{ml}) \dagger\end{array}$ & staphylokinase \\
\hline $\begin{array}{l}\text { V4 } \\
\left.\text { L62 (leuc }{ }^{l}\right) \\
\text { L62 (A) } \\
\text { BF24 (kin-) } \\
\text { BF34 (F) }\end{array}$ & $\begin{array}{c}\mathbf{R} \\
\mathbf{S}(100) \\
\mathbf{R} \\
\mathbf{R} \\
\mathbf{R}\end{array}$ & $\begin{array}{c}\mathbf{R} \\
\mathbf{R} \\
\mathbf{R} \\
\mathbf{S}(5000) \\
\mathbf{R}\end{array}$ & $\begin{array}{l}29 \\
29 / \mathrm{N} / 7 /+ \\
29 \\
29 / 81 /+ \\
29\end{array}$ & $\begin{array}{l}0.25 \\
0.0078 \\
0.25 \\
0.25 \\
0.25\end{array}$ & $\begin{array}{l}+ \\
+ \\
+ \\
+\end{array}$ \\
\hline
\end{tabular}

* $\mathrm{R}=$ resistant; $\mathrm{S}=$ sensitive at the stated number of $\mathrm{RTD}$ given in brackets.

$\dagger$ The amount produced in culture after shaking for $8 \mathrm{~h}$ at $37^{\circ} \mathrm{C}$ in CCY medium is given. After shaking for $16 \mathrm{~h}$, strains $\mathrm{V} 4$ and $\mathrm{L} 62($ leucl $)$ produced $1 \cdot 1 \mathrm{~L}+$ and $0 \cdot 1 \mathrm{~L}+$ per ml respectively (see Gladstone and van Heyningen, 1957). 
TABLE V

Haemolysin pattern and haemolytic potency (MHD) of two culture supernates $(A, B)$ of the wild-type strain and its mutants

\begin{tabular}{|c|c|c|c|c|c|c|c|}
\hline \multirow{3}{*}{ Strain } & \multicolumn{3}{|c|}{$\begin{array}{l}\text { Haemolysin pattern on blood agar } \\
\text { with RBC of }\end{array}$} & \multicolumn{4}{|c|}{$\begin{array}{l}\text { Haemolytic potency (MHD) of culture } \\
\text { supernates A and B titrated against } \\
\text { RBC of }\end{array}$} \\
\hline & \multirow{2}{*}{ rabbit } & \multirow[t]{2}{*}{ sheep } & \multirow[t]{2}{*}{$\overrightarrow{\operatorname{man}}$} & \multicolumn{2}{|c|}{ rabbit } & \multicolumn{2}{|c|}{$\operatorname{man}$} \\
\hline & & & & A & B & A & B \\
\hline 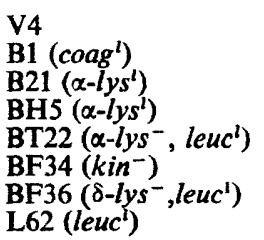 & $\begin{array}{c}\alpha, \delta \\
\alpha, \delta \\
\delta \\
\delta \\
\delta \\
\alpha, \delta \\
\alpha, \delta\end{array}$ & $\begin{array}{c}\alpha, \delta \\
\alpha, \delta \\
\delta \\
\delta \\
\delta \\
\alpha, \delta \\
\alpha, \delta\end{array}$ & $\begin{array}{l}\delta \\
\delta \\
\delta \\
\delta \\
\delta \\
\delta \\
\delta\end{array}$ & $\begin{array}{r}512 \\
512 \\
64 \\
64 \\
8 \\
512 \\
128 \\
512\end{array}$ & $\begin{array}{r}256 \\
256 \\
64 \\
64 \\
4 \\
N D \\
64 \\
256\end{array}$ & $\begin{array}{l}64 \\
64 \\
32 \\
32 \\
16 \\
64 \\
32 \\
64\end{array}$ & $\begin{array}{r}32 \\
64 \\
16 \\
16 \\
4 \\
\text { ND } \\
16 \\
32\end{array}$ \\
\hline
\end{tabular}

$\mathrm{ND}=$ Not done; $-=$ no haemolysis

lost the ability to produce $\alpha$ - and $\delta$-lysin. Unlike $\alpha$-lysin, $\delta$-lysin is thermostable and not neutralisable by $\alpha$-antitoxin. Representative results, summarised in table VI, show that the culture supernate of the wild type retained weak haemolytic activity after heating and neutralisation. This residual titre was presumably due to a thermostable, non-neutralisable haemolysin-probably $\delta$-lysin. The supernates of mutants B21 $\left(\alpha-l y s^{l}\right)$ and BH5 $\left(\alpha-l y s^{l}\right)$, strains which no longer gave $\alpha$-lysin activity on blood agar, had less activity against rabbit $\mathrm{RBC}$ than did the wild-type supernate. This activity decreased further after heating and neutralisation. These strains thus still produced $\alpha$-lysin; i.e., they were leaky mutants. The very weak haemolytic activity of the supernate of mutant BT22 ( $\alpha-l y s^{-}$, leucl) was unaffected by the heating or neutralisation; this strain must thus make $\delta$-lysin only, but probably less than the wild type. The supernate of mutant BS36 ( $\delta$-lys $s^{-}$, leucl $\left.{ }^{l}\right)$ could be completely inactivated by heating, and was completely neutralised by $\alpha$-antitoxin; this strain must thus produce $\alpha$-lysin alone.

Finally, we investigated whether culture supernates of the wild type and of strain BS36 ( $\delta-l y s^{-}$, leucl) contained the same amount of $\alpha$-lysin. For this purpose, serial dilutions of $\alpha$-antitoxin (8 IU per ml) were made in $20 \%$ steps. These dilutions were then added to the culture supernates and the mixtures were titrated for haemolytic activity against rabbit RBC. The minimum neutralising dose for the supernate of mutant BS36 ( $\delta$-lys-, leucl) was $1.28 \mathrm{IU}$ per ml. Supernate of the wild type treated with $\alpha$-antitoxin at that concentration retained only residual haemolytic activity that was not further reduced with an excess of antitoxin. Mutant BS36 $\left(\delta-l y s^{-}\right.$, leuc $\left.{ }^{l}\right)$ thus appeared to produce as much $\alpha$-lysin as the wild type. 
TABLE VI

Haemolytic potency (MHD) of culture supernate $(B)$ against rabbit and human $R B C$ before and after heating or treatment with $\alpha$-antitoxin

\begin{tabular}{|c|c|c|c|c|c|c|}
\hline \multirow{3}{*}{ Strain } & \multicolumn{6}{|c|}{ Haemolytic potency (MHD) } \\
\hline & \multicolumn{3}{|c|}{$\begin{array}{l}\text { against rabbit } R B C \text { with culture } \\
\text { supernate subjected to }\end{array}$} & \multicolumn{3}{|c|}{$\begin{array}{c}\text { against human } \mathrm{RBC} \text { with culture } \\
\text { supernate subjected to }\end{array}$} \\
\hline & $\begin{array}{c}\text { no } \\
\text { treatment }\end{array}$ & heat & $\alpha$-antitoxin & $\begin{array}{c}\text { no } \\
\text { treatment }\end{array}$ & heat & $\alpha$-antitoxin \\
\hline $\begin{array}{l}\text { V4 } \\
\text { B21 }\left(\alpha-l y s^{l}\right) \\
\text { BH }\left(\alpha-l y s^{l}\right) \\
\text { BT22 }\left(\alpha-l y s^{-}, l e u c^{l}\right) \\
\text { BS36 }\left(\delta-l y s^{-}, \text {leuc }^{l}\right)\end{array}$ & $\begin{array}{r}256 \\
64 \\
64 \\
4 \\
64\end{array}$ & $\begin{array}{r}16 \\
8 \\
8 \\
4 \\
0\end{array}$ & $\begin{array}{r}16 \\
8 \\
8 \\
4 \\
0\end{array}$ & $\begin{array}{r}32 \\
16 \\
16 \\
4 \\
16\end{array}$ & $\begin{array}{l}4 \\
4 \\
4 \\
4 \\
0\end{array}$ & $\begin{array}{l}4 \\
4 \\
4 \\
4 \\
0\end{array}$ \\
\hline
\end{tabular}

\section{Discussion}

These experiments were performed with the object of producing mutants differing from the wild type preferably in one characteristic only, so that the contribution of various products of $S$. aureus to virulence could be investigated. Mutants of this type were found for $\alpha$-lysin, coagulase, leucocidin and staphylokinase. However, with the exception of the staphylokinase mutant, the mutants still retained some activity of the specific protein. This must either be ascribed to a diminished production of this protein or to production of a modified protein ("leaky" mutants).

In these studies, treatment of $S$. aureus with EMS gave rise to a wide variety of mutants. Except in two cases, systematised combined loss of a restricted number of staphylococcal characteristics was not observed. The loss of $\delta$ lysin production was always coupled with an appreciable reduction in leucocidin production. Mutants that had lost all the properties characteristic of $S$. aureus, however, were found relatively often. These mutants all had a lower growth rate than the wild type in vitro, and were insensitive to the phages of the phage-typing system for $S$. aureus. These mutants did not differ from $S$. epidermidis on the basis of the criteria of Baird-Parker (1963).

Experimental evidence that the capacity of the wild-type strain V4 to produce staphylokinase and leucocidin is based on two independent lysogenic conversions has been described elsewhere (van der Vijver, van Es-Boon and Michel, 1972). In the present study, it could be shown for two mutants that changes in these properties were due to a change in the prophage genotype of the wild type. Loss of staphylokinase in mutant BF34 (kin-) was found to be due to loss of a group-F phage, and diminished leucocidin production of mutant L62 (leucl) to loss of a group-A phage. However, this was not the case in mutants in which the loss of staphylokinase or leucocidin was coupled with loss of other properties. 


\section{SUMMARY}

Staphylococcus aureus strains were treated with ethylmethane sulphonate with the object of obtaining mutants that differed from the wild type in one of the properties that might contribute to virulence.

Mutants with isolated loss or deficient production of $\alpha$-haemolysin, coagulase, leucocidin and staphylokinase were obtained. Changes in more than one property were often observed. The loss of $\delta$-lysin production was always coupled with an appreciable reduction in $\mathrm{P}-\mathrm{V}$ leucocidin production. With that exception, systematised combined loss of a restricted number of staphylococcal characteristics was not observed. Mutants that had lost all characteristics of $S$. aureus were phage-resistant. Isolated loss of staphylokinase production and deficient P-V leucocidin production were found to be due to the independent loss of two prophages.

We wish to thank Dr R. T. H. Scholtens and Dr J. Borst (Rijksinstituut voor de Volksgezondheid, Bilthoven, The Netherlands) for the phage-typing work; Dr J. R. J. Bänffer for advice concerning the leucocidin experiments; Dr Elizabeth $H$. Ashesov for the generous supply of antiphage sera; and Mrs E. D. Peerlkamp-Jansen for the preparation of the manuscript.

\section{REFERENCES}

Agarwal, D. S. 1967. Subcutaneous staphylococcal infection in mice. II. The inflammatory response to different strains of staphylococci and micrococci. Br.J. exp. Path., 48, 468.

Arbuthnotr, J. P. 1970. Staphylococcal $\alpha$-toxin. In Microbial toxins, vol. III, edited by T. C. Montie, S. Kadis and S. J. Ajl, New York and London, p. 189.

Arbuthnott, J. P., Gemmell, C. G., Kent, J. ANd Lyell, A. 1969. Haemolysin and enzyme patterns of coagulase-positive staphylococci isolated from toxic epidermal necrolysis, Ritter's disease and impetigo contagiosa. J. med. Microbiol., 2, 479.

Batrd-PARKer, A. C. 1963. A classification of micrococci and staphylococci based on physiological and biochemical tests. J. gen. Microbiol., 30, 409.

BARBER, M. AND KUPER, S. W. A. 1951. Identification of Staphylococcus pyogenes by the phosphatase reaction. J. Path. Bact., 63, 65.

BaUtz, E. AND FreEse, E. 1960. On the mutagenic effect of alkylating agents. Proc. natn Acad. Sci. USA, 46, 1585.

Blair, J. E. AND Williams, R. E. O. 1961. Phage typing of staphylococci. Bull. Wld Hlth Org., 24, 771.

Burnet, F. M., KeOGH, E. V. AND Lush, D. 1937. The immunological reactions of the filterable viruses. Aust. J. exp. Biol. med. Sci., 15, 231.

Cadness-Graves, B., Williams, R., Harper, G. J. and Miles, A. A. 1943. Slide-test for coagulase-positive staphylococci. Lancet, 1, 736.

Cawdery, M., Foster, W. D., Hawgood, B. C. and Taylor, C. 1969. The role of coagulase in the defence of Staphylococcus aureus against phagocytosis. Br.J. exp. Path., 50, 408.

EleK, S. D. AND LeVY, E. 1950. Distribution of haemolysins in pathogenic and nonpathogenic staphylococci. J. Path. Bact., 62, 541.

FOSTER, W. D. 1971. The relationship between the pathogenicity of Staphylococcus aureus for the mouse and its pathogenicity for man and the guinea pig. Br.J. exp. Path., 52, 307.

Gershon, A. AND Gladstone, G. P. 1968. Immunofluorescent demonstration of staphylococcal leucocidin components F and S. Br. J. exp. Path., 49, 477.

Gladstone, G. P. and van Heyningen, W. E. 1957. Staphylococcal leucocidins. Br.J. exp. Path., 38, 123.

Gladstone, G. P., Mudd, S., Hochstein, H. D. and Lenhart, N. A. 1962. The assay of anti-staphylococcal leucocidal components ( $\mathrm{F}$ and $\mathrm{S}$ ) in human serum. $B r . J$. exp. Path., 43, 295. 
HaYes, W. 1968. The genetics of bacteria and their viruses, 2nd ed., Oxford and Edinburgh, p. 307.

HiLl, M. J. 1968. A staphylococcal aggressin. J. med. Microbiol., 1, 33.

Jessen, O., Rosendal, K., Bülow, P., Faber, V. and Eriksen, K. R. 1969. Changing staphylococci and staphylococcal infections: a ten year study of bacteria and cases of bacteremia. New Eng. J. Med., 281, 627.

KaPRAL, F. A. AND LI, I. W. 1960 . Virulence and coagulases of Staphylococcus aureus. Proc. Soc. exp. Biol. Med., 104, 151.

LACK, C. H. AND WaIlling, D. G. 1954. A study of 435 strains of Staphylococcus pyogenes with reference to factors which may contribute to pathogenicity. J. Path. Bact., 68, 431.

LOVEless, A. AND Howarth, S. 1959. Mutation of bacteria at high levels of survival by ethyl methane sulphonate. Nature, Lond., 184, 1780.

McClatchy, J. K. AND Rosenblum, E. D. 1966. Biological properties of $\alpha$-toxin mutants of Staphylococcus aureus. J. Bact., 92, 575.

MeYnell, G. G. AND MeYnell, E. 1965. Theory and practice in experimental bacteriology, Cambridge, p. 26.

Miles, A. A., MisRA, S. S. AND IRwin, J. O. 1938. The estimation of the bactericidal power of the blood. J. Hyg., Camb., 38, 732.

Mudd, S., Gladstone, G. P. And Lenhart, N. A. 1965. The antigenicity in man of staphylococcal leucocidin toxoid, with notes on therapeutic immunization in chronic osteomyelitis. Br.J. exp. Path., 46, 455.

Noble, W. C. 1966. Virulence and the biochemical characters of staphylococci. J. Path. Bact., 91, 181.

Otsuj, N., Sekiguchi, M., Iijima, T. And TAKagi, Y. 1959. Induction of phage formation in the lysogenic Escherichia coli K-12 by mitomycin C. Nature, Lond., 184, 1079.

SIERRA, G. 1957. A simple method for the detection of lipolytic activity of microorganisms and some observations on the influence of the contact between cells and fatty substrates. Antonie van Leeuwenhoek, 23, 15.

SkeGG, J. L. AND ANDERSON, S. G. 1969. International reference preparation of antistaphylococcal P-V leucocidin serum. Bull. Wld Hlth Org., 40, 593.

SMith, R. F. AND Willett, N. P. 1968. Rapid plate method for screening hyaluronidase and chondroitin sulfatase-producing microorganisms. Appl. Microbiol., 16, 1434.

ViJVER, J. C. M. vaN DER, KRAAYeVELd, C. A. AND MiChel, M. F. 1972. A solid medium for visual demonstration of coagulase production by Staphylococcus aureus. J. clin. Path., 25, 450.

ViJVer, J. C. M. VAN Der, VAN Es-Boon, M. M. AND Michel, M. F. 1972. Lysogenic conversion in Staphylococcus aureus to leucocidin production. J. Virol., 10, 318.

ViJVer, J. C. M. VAN DeR, van Es-Boon, M. M. AND Michel, M. F. 1974. The enhancing effect of cell-wall aggressin on the virulence of Staphylococcus aureus in normal and irradiated mice and in man. Antonie van Leeuwenhoek, 40, 49.

ViJver, J. C. M. van DeR, van Es-Boon, M. M. AND Michel, M. F. 1975. A study of virulence factors with induced mutants of Staphylococcus aureus. J. med. Microbiol., 8, 279.

Williams, R. E. O. 1963. Healthy carriage of Staphylococcus aureus: its prevalence and importance. Bact. Rev., 27, 56.

Winkler, K. C., De WaART, J., Grootsen, C., Zegers, B. J. M., Tellier, N. F. AND VERTREGT, C. D. 1965. Lysogenic conversion of staphylococci to loss of $\beta$-toxin. J. gen. Microbiol., 39, 321.

Wiseman, G. M. 1970. The beta- and delta-toxins of Staphylococcus aureus. In Microbial toxins, vol. III, edited by T. C. Montie, S. Kadis and S. J. Ajl, New York and London, p. 237.

Woodin, A. M. 1959. Fractionation of a leucocidin from Staphylococcus aureus. Biochem. J., 73, 225. 